\title{
The possibility of DIC system application in numerical models updating
}

\author{
Barbara Turoń1, Bartosz Miller² \\ ${ }^{1}$ Department of Structural Mechanics; Faculty of Civil and Environmental Engineering and Architecture; \\ Rzeszow University of Technology; Powstańców Warszawy 12, 35-959 Rzeszów, Poland \\ bturon@prz.edu.pl; ORCID:0000-0002-7013-6304 \\ ${ }^{2}$ Department of Structural Mechanics; Faculty of Civil and Environmental Engineering and Architecture; \\ Rzeszow University of Technology; Powstańców Warszawy 12, 35-959 Rzeszów, Poland \\ bartosz.miller@prz.edu.pl; ORCID:0000-0003-3318-4339
}

\begin{abstract}
The paper presents the results of updating of numerical models of the rectangular steel plate members in a plane state of stress, the updated parameter was a support length. Three different members loaded in a static or dynamic way were analyzed. The article shows examples of purely numeric updating. The data used to the update of numerical models was obtained from numerical simulations and it corresponds to the data, which can be measured by using the Digital Image Correlation (DIC) system. The main aim of the paper is to check the possibilities of the DIC system application in updating of numerical models.
\end{abstract}

Keywords: Digital Image Correlation, DIC system accuracy, optimization, updating of numerical models

\section{Introduction}

Reproduction and simulation of the behavior of real structures using numerical models is an invaluable source of information for engineers. The possibility of numerically generating a structure response may significantly shorten the design and the experimental research processes. It can also help to avoid high costs and technical difficulties connected with a performance of experimental measurements. The creation of precise models of structural elements, element connections and complete structures is a paramount issue, both in analyzes of conditions of real structures and in the design of the structures. Numerical models are continuously being improved thanks to technological progress, development of the computing power of computers and the development of advanced procedures for engineering calculations. Nevertheless, inaccuracies still appear in numerical models. The inaccuracies can be caused by a variety of factors. For example, they can be associated with the modeling of support conditions or they can appear as a result of the material heterogeneity. To eliminate the inaccuracies, numerical models can be updated. It means they can be corrected and improved on the basis of the results of the experimental research (the comparison of the results of the experimental research carried out on the real structure with the results of numerical simulations of the model of the structure which is used to change and to improve the numerical models) [1]. 


\section{Digital image correlation - the method and its accuracy}

\subsection{Characteristics of the Digital Image Correlation method}

Digital Image Correlation (DIC) is a full-field image analysis method, based on high-resolution grey value digital images of an object under a load. The images are recorded during a change of shape and/or location of the examined object. This method is used for the determination of contours, displacements and strains of investigated objects. This method allows for measurements in two-dimensional (2D) or three-dimensional (3D) spaces. Compared to the traditional measurement methods, DIC gives a possibility to acquire in a very short time a very large amount of data on displacements and strains of the tested object from its entire surfaces, or in case of a larger element, from surface fragments, moreover in a non-contact way [2-4].

During the measurement process, the image of the investigated object is taken before the deformation process and series of images are recorded after applying the load to the object. Digital Image Correlation uses the correlation algorithm for the data evaluation. To achieve a successful correlation between the two images, it is necessary to apply random speckle patterns on the object surface by spraying the white-and-black pattern onto the sample surface. One of the recorded images is selected as reference (most often it is an image of the object taken before its loading). A regular grid with equidistant grid points is laid over the image of the reference camera (if there is more than one camera, only one is selected as reference) at the reference step. Each grid point defines the center of a squared image region in the reference image. This square area around the grid point is called a facet (see Fig. 1). The correlation algorithm uses facets in order to identify the corresponding area of another image. It locates every facet of the reference image in subsequent deformed images. For 3D DIC the image correlation algorithm uses these facets for determining the 3D-position and tangential plane of the underlying object surface for each of the grid points. The correlation algorithm is based on the tracking of the grey value pattern in small local Adjacent facets so each facet must contain a characteristic part of the pattern with good contrast features. The minimal size of the facet is limited by the size and roughness of the stochastic pattern on the object surface [2-6].

The DIC measurement results in a determination of the contour and the deformation of the investigated object and obtaining data of the strain state of the object. The direct measurement result of DIC are displacements of the object in two or three directions. The calculations of strains are based on the value of displacements. The measurement quality relies on exact knowledge of the parameters of the DIC system, the determination of these parameters is made in a process called calibration. The calibration is obtained by recording images of a unified calibration target under different perspective views. A bundle-adjustment algorithm is used to determine the DIC parameters. This knowledge of the parameters allows to evaluate the geometry of the object from captured camera images. An object point is identified in the images of the two cameras by applying the correlation algorithm and finding homologous points. Taking the imaging parameters into account, the contour of the object can be calculated. Calculating the transformation parameters for images under different conditions of loading, both the displacement vector and deformation for each facet can be determined. Considering the object curvature, the strain can be calculated by the parameter of the affine transformation and by the gradients of the deformation [2-6].

The application of the image correlation method in mechanics dates back to the $1980 \mathrm{~s}$ [7-9], however, only in recent years, intensive research has allowed for significant development and improvement of this method, among others by using high-resolution digital 
cameras in measurements. An example of a measuring system based on the digital image correlation method is the Dantec Dynamics Q-450 system. The basic elements of the system are two high-speed digital cameras, the control computer with Istra 4D software, the Timing Box synchronizing multiple sensors and ensuring that the images are recorded at the same time, and calibration targets. The measurement carried out using Q-450 system consists of several stages: the sample preparation for the test by creating a random pattern of points on its surface, the preparation of the measurement set-up and the hardware configuration, the system calibration by using special calibration targets, the proper measurement i.e. the images registration during sample loading, the analysis of saved images based on correlation, and the visualization of obtained results $[3,6]$.

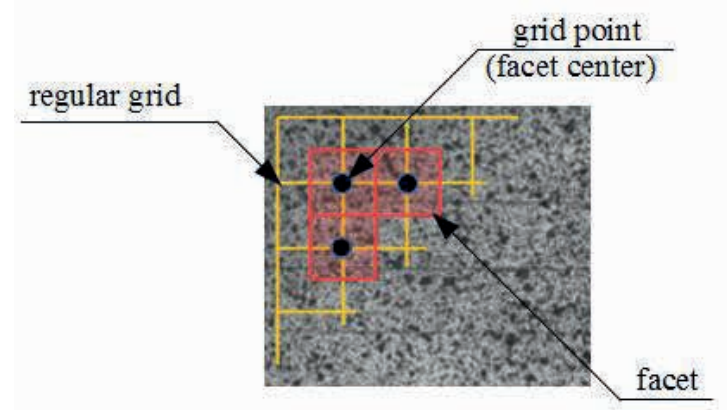

Fig. 1. Virtual grid of points and facets grid

\subsection{DIC system accuracy on the example of the Q-450 system}

Accuracy of the measurement system is a very important issue in the research and planning of the tests. Over the past few years, the accuracy of DIC has been investigated by many researchers. For example, Guoqing Gu et al. [10] studied the influence of the non-uniform intensity images on the measurement accuracy of DIC (influence of non-uniform illumination was analyzed through the comparison of experimental results of DIC by the use of speckle patterns with both uniform and non-uniform intensity distributions, and a new correctional method was proposed). Hack E. et al. [11] described a simple reference material for establishing the minimum measurement uncertainty of optical systems for measuring 3D surface displacement fields in deforming objects, as well as its use. Lutowski Z. et al. [12] decided to verify the accuracy of the displacement detection of the DIC method by comparing the results with real displacement, and performed the tests on a special system for fatigue properties testing of micro-objects (MFS), which allowed to estimate the measuring errors for the DIC method. Zappa E. et al. [13] discussed the DIC uncertainty assessment in dynamic applications and evaluation and improvement of DIC uncertainty in dynamic conditions. Krawczyk $Ł$. et al. [14] also wrote about the inaccuracies of the DIC system. The estimated measurement of the inaccuracies for the Aramis system and gave some practical information about determining compatibility between the crack width measured traditionally and by the Aramis. They also discussed the influence of the facet size on the crack width.

Herein, the accuracy of the digital image system is presented on the example of the Q-450 System from Dantec Dynamics with Phantom v341 cameras. Phantom v341 has the possibility of image recording with a frequency of up to $130 \mathrm{kHz}$. The full image resolution is $2560 \times 1600$ pixels. The maximum speed of the camera at full image resolution is 800 frames per second [15]. The cameras of the Q-450 System and the system scheme is shown in Figure 2. 

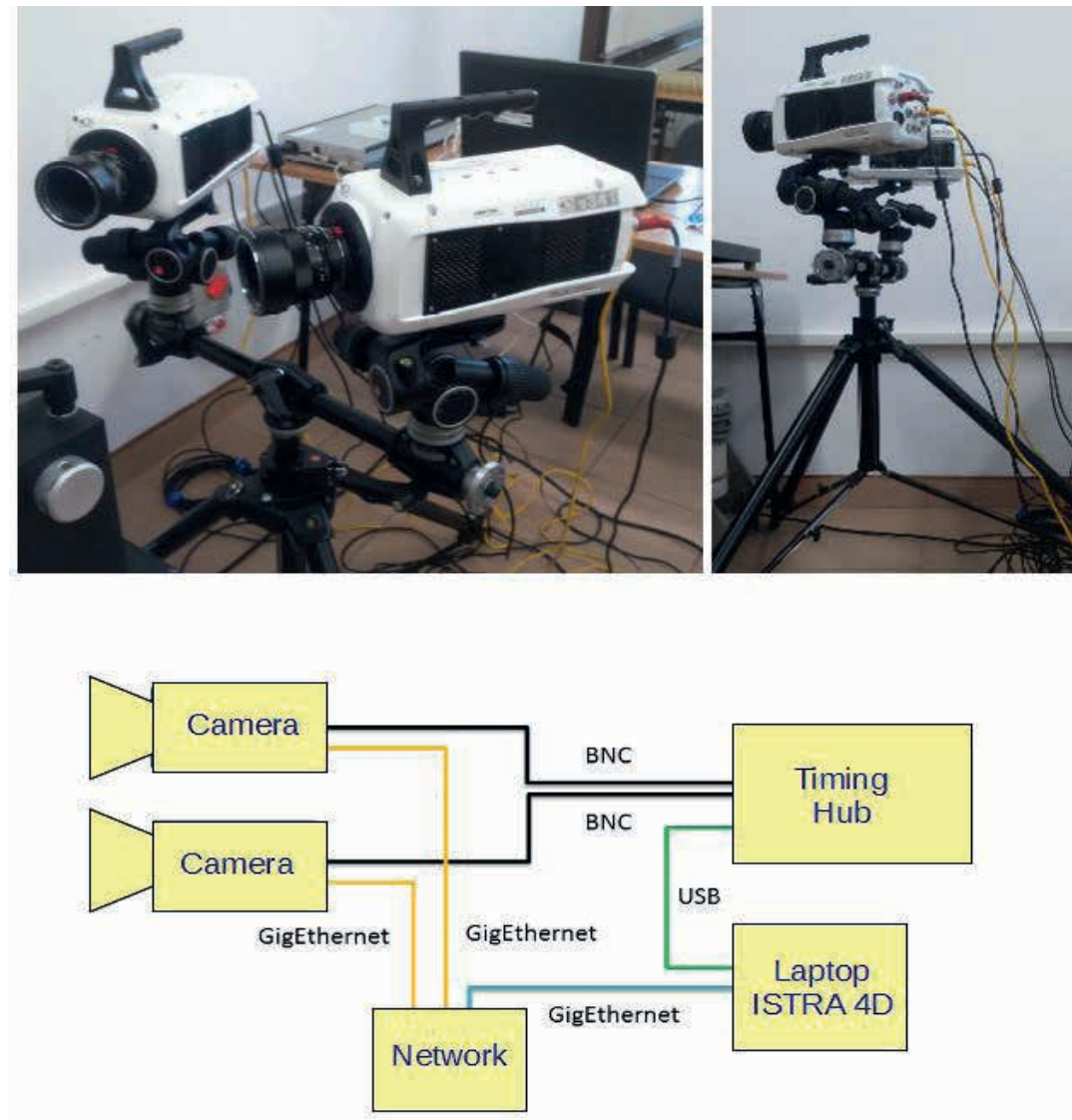

Fig. 2. Q-450 System [6]

The system accuracy regarding the displacements measurement given by Dantec Dynamics is better than 0,01 pixels $[3,12,16]$. This value was verified during experimental research. The investigated object was a plane, a two-story portal frame (see [17]). The horizontal and vertical elements of the frame were made of I-beam (IPE80) and S355 steel. The length of the elements of the frame was $1.6 \mathrm{~m}$. For the accuracy test, the area located in the middle of the lower beam of the frame was chosen (see Figure 3). This area had a dimension of $100 \mathrm{~mm} \mathrm{x}$ $50 \mathrm{~mm}$ and it was located centrally to the symmetry axis of the frame. The image resolution corresponding to the selected part $100 \mathrm{~mm}$ x $50 \mathrm{~mm}$ was 1516 x 758 pixel. Thus, 1 pixel had an approximate dimension of $0,066 \mathrm{~mm}$. In reference to the system accuracy given by Dantec Dynamics, the measurement error should be smaller than $0,00066 \mathrm{~mm}$. The error size of the displacement $[\mathrm{mm}]$ for five points located on the selected surface was measured. The points were in four corners of the surface and in the middle of the surface. A thousand images were registered during the research, and therefore 1000 values of the uncertainty at each point were obtained from ISTRA software. The average value was calculated, and the result was $0,00046 \mathrm{~mm}$. The maximum error value obtained from measurements was $0,00081 \mathrm{~mm}$ and the minimum error value was $0,00019 \mathrm{~mm}$ (see Figure 4). 


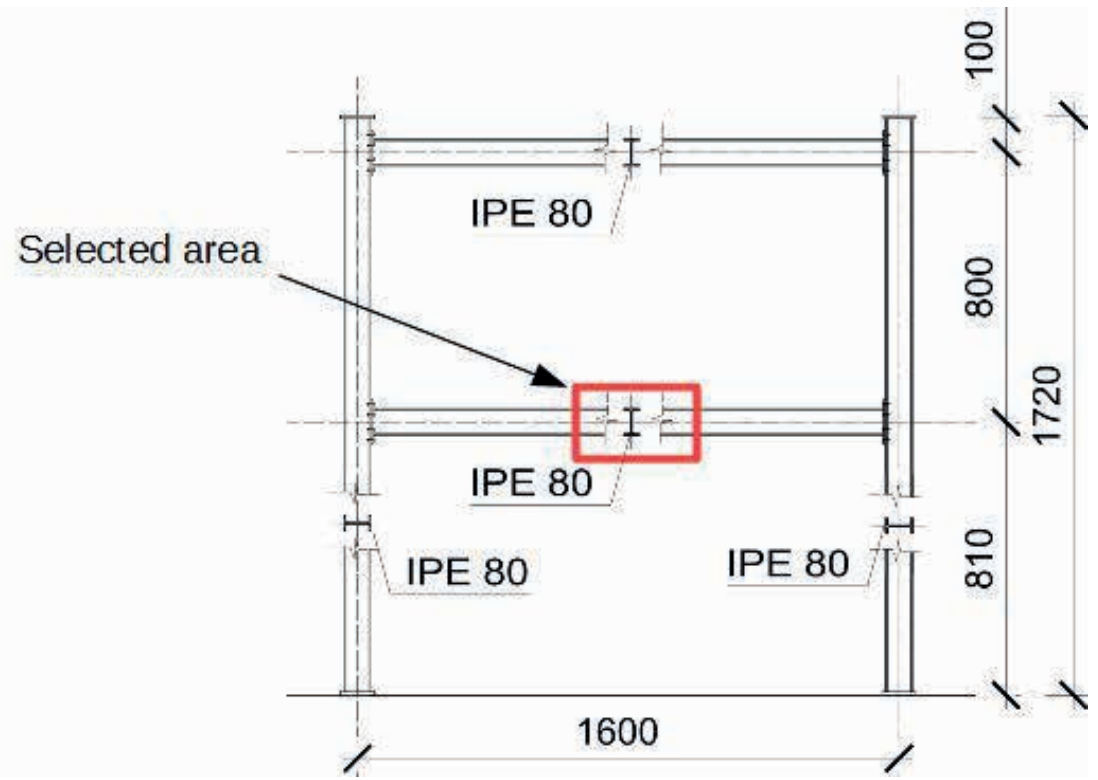

Fig. 3. Area of the frame selected for the accuracy test [17]

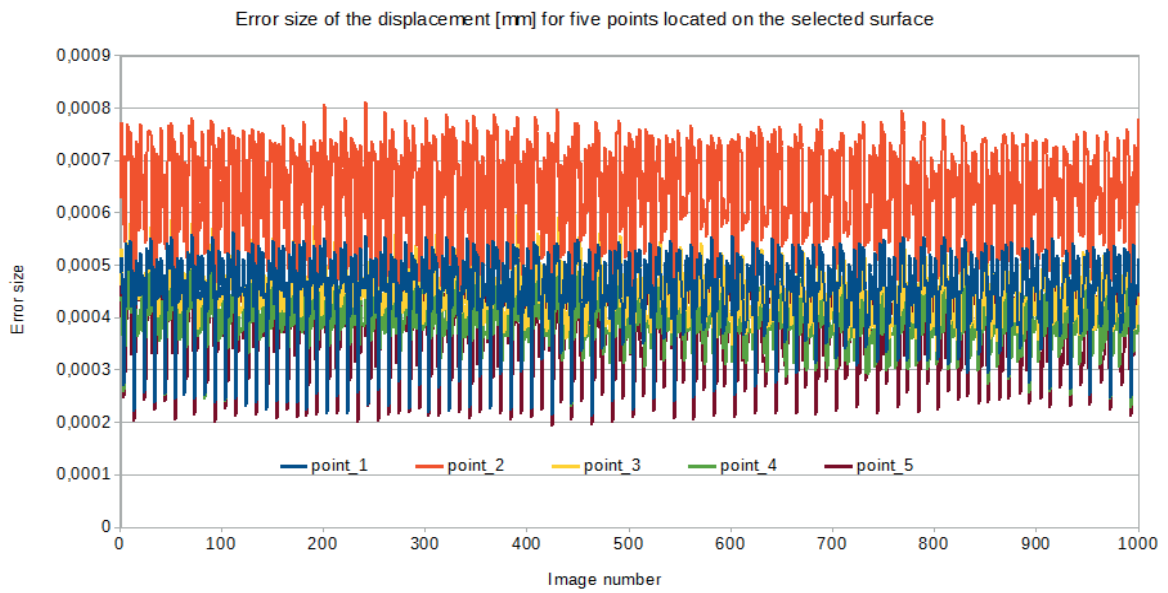

Fig. 4. Measurement errors

The size of measurement errors is closely related to the size of the measurement field. The larger measurement field, the bigger measurement errors and the smaller measurement accuracy. The size of measurement errors is also connected with the resolution of the digital image. The higher the image resolution, the smaller the measurement error. This dependence is very important in planning DIC measurements. The relationship between the measurement field size and the error size for the system Q-450 assuming 1600 pixel x 1600 pixel image resolution is presented in Table 1 (1600 pixel is the biggest pixel number at the height of the image for camera Phantom v341 [15]). 
Table 1. Accuracy of Q-450 System with Phantom v341 cameras

\begin{tabular}{ll}
\hline Measurement field size $[\mathrm{mm}]$ & Measurement error size $[\mathrm{mm}]$ \\
\hline $16 \times 16$ & 0,0001 \\
\hline $32 \times 32$ & 0,0002 \\
\hline $48 \times 48$ & 0,0003 \\
\hline $64 \times 64$ & 0,0004 \\
\hline $80 \times 80$ & 0,0005 \\
\hline $96 \times 96$ & 0,0006 \\
\hline $112 \times 112$ & 0,0007 \\
\hline $128 \times 128$ & 0,0008 \\
\hline $160 \times 144$ & 0,0009 \\
\hline $1600 \times 1600$ & 0,0010 \\
\hline
\end{tabular}

\section{Affine transformation and affine parameters}

The affine transformation (also called the affinity) is a geometrical transformation that preserves the parallelism of lines but not the lengths and angles. It means that sets of parallel lines remain parallel after the affine transformation, but this transformation does not necessarily preserve angles between lines or distances between points, though it does preserve ratios of distances between points lying on a straight line. In general, an affine transformation allows for rotations, translations and scaling (different scaling in two directions).

The affine transformation can be represented with the following matrix:

$$
\left[\begin{array}{lll}
a_{0} & a_{1} & a_{2} \\
b_{0} & b_{1} & b_{2}
\end{array}\right]\left[\begin{array}{lll}
a_{0} & a_{1} & a_{2} \\
b_{0} & b_{1} & b_{2}
\end{array}\right]
$$

where:

$\left[\begin{array}{l}a_{0} \\ b_{0}\end{array}\right]\left[\begin{array}{l}a_{0} \\ b_{0}\end{array}\right]$ is the translation vector, it simply moves the points,

$\left[\begin{array}{ll}a_{1} & a_{2} \\ b_{1} & b_{2}\end{array}\right]\left[\begin{array}{ll}a_{1} & a_{2} \\ b_{1} & b_{2}\end{array}\right]$

is a rotation matrix. This matrix defines the kind of transformation that will be performed, scaling and rotation.

If $x$ and $y$ are the coordinates of a point, the transformation can be done by a simple multiplication:

$$
\left[\begin{array}{l}
X \\
Y
\end{array}\right]=\left[\begin{array}{lll}
a_{0} & a_{1} & a_{2} \\
b_{0} & b_{1} & b_{2}
\end{array}\right]\left[\begin{array}{l}
1 \\
x \\
y
\end{array}\right]\left[\begin{array}{l}
X \\
Y
\end{array}\right]=\left[\begin{array}{lll}
a_{0} & a_{1} & a_{2} \\
b_{0} & b_{1} & b_{2}
\end{array}\right]\left[\begin{array}{l}
1 \\
x \\
y
\end{array}\right]
$$

The parameters $a_{0}, a_{1}, a_{2}, b_{0}, b_{1}, b_{2}$ are called the affine ones. They can describe precisely how the figure consisting of three points is transformed after changing the positions of these points [18-20].

The pseudo-affine transformation (bilinear transformation) was used in this article. This transformation does not preserve lengths and angles, and as opposed to the affine transformation, it does not preserve parallelism. However, it still preserves collinearity and incidence. The pseudo-affine transformation can be represented as the transformation of an arbitrary quadrangle (i.e. a system of four points) into another one. 
The pseudo-affine transformation can be represented with the following matrix:

$\left[\begin{array}{llll}a_{0} & a_{1} & a_{2} & a_{3} \\ b_{0} & b_{1} & b_{2} & b_{3}\end{array}\right]\left[\begin{array}{llll}a_{0} & a_{1} & a_{2} & a_{3} \\ b_{0} & b_{1} & b_{2} & b_{3}\end{array}\right]$

where:

$\left[\begin{array}{l}a_{3} \\ b_{3}\end{array}\right]\left[\begin{array}{l}a_{3} \\ b_{3}\end{array}\right]$ is the distortion vector.

If $x$ and $y$ are the coordinates of a point, the transformation can be done by the simple multiplication:

$$
\left[\begin{array}{l}
X \\
Y
\end{array}\right]=\left[\begin{array}{llll}
a_{0} & a_{1} & a_{2} & a_{3} \\
b_{0} & b_{1} & b_{2} & b_{3}
\end{array}\right]\left[\begin{array}{c}
1 \\
x \\
y \\
x y
\end{array}\right]\left[\begin{array}{l}
X \\
Y
\end{array}\right]=\left[\begin{array}{llll}
a_{0} & a_{1} & a_{2} & a_{3} \\
b_{0} & b_{1} & b_{2} & b_{3}
\end{array}\right]\left[\begin{array}{c}
1 \\
x \\
y \\
x y
\end{array}\right]
$$

In the case of the pseudo-affine transformation there are eight affine parameters as follows: $a_{0}, a_{1}, a_{2}, a_{3}, b_{0}, b_{1}, b_{2}, b_{3}$ (Fig. 5).

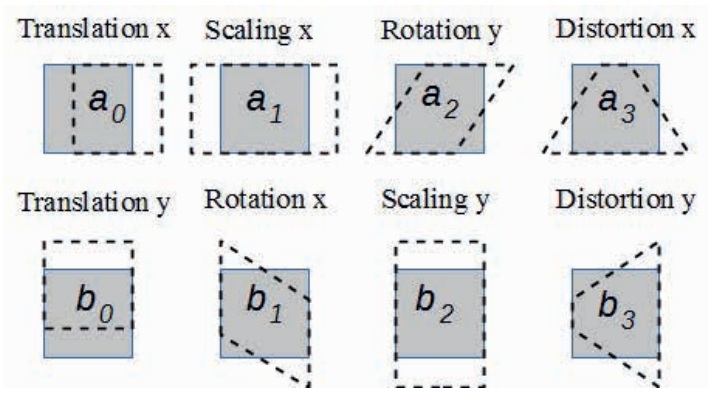

Fig. 5. Affine parameters [21]

Knowing the coordinates of four points before and after the load application, the affine parameters determining the transformation of the rectangular region defined by the four points can be calculated [19-21].

\section{The aim of the paper}

The aim of this paper is to check numerically the possibility of using the DIC system in updating simple numerical models. The paper contains the examples of a purely numeric updating, the data used to update were obtained from numerical simulations and they correspond to the data which can be measured by using the DIC system. Various variants of using the DIC in measurements were considered, i.e. using the system with one camera, two cameras or four cameras. The most beneficial location and size of the area from which data for model updating were obtained were being looked for. The type of data giving the best updating results was being investigated.

In this paper, the models of three steel plate members in a plane state of stress were investigated. The members were loaded statically or dynamically. The updated parameter was a support length of the members, based on the displacement difference or the difference of the affine parameters obtained for pseudo-experimental models. In the case of the static load, 
differences between the displacement values of selected nodes of the models were minimized, in the case of the dynamic load, differences between the affine parameters for selected quadrangular fragments of the models were minimized. The displacements obtained from models corresponding to the experimental research were cut off to the theoretical accuracy of the DIC Q-450 system.

In the article, the DIC Q-450 system and its accuracy are presented. Then the affine transformation and affine parameters are described. The updated models of steel plate members conducted numerical analyzes and their results are shown. Finally, the conclusions are formulated.

\section{Investigated objects and updating their models}

\subsection{Investigated steel plate members}

The subject of updating were models of steel plate members. Three plates in plane stress were analyzed. The first analyzed plate $A$ had dimensions of $100 \mathrm{~mm}$ x $50 \mathrm{~mm}$ and a thickness of $5 \mathrm{~mm}$, the second plate $B$ was $1000 \mathrm{~mm}$ x $200 \mathrm{~mm}$ x $20 \mathrm{~mm}$, the third plate $C$ was $1000 \mathrm{~mm}$ x $1000 \mathrm{~mm}$ x $20 \mathrm{~mm}$ (see Figure 6). All members were partially fixed along their bottom edge. The length of the fixed support varied from $1 / 20$ of the plate length to the whole length. All plates were loaded by one concentrated force acting vertically in the right upper corner of the plate. For all created models two types of loads were defined, a static load and a dynamic load with a varying maximal value (from $1 \mathrm{kN}$ to $10 \mathrm{kN}$ with step $1 \mathrm{kN}$ ), with the time history of the dynamic load shown in Fig. 7. The time step assumed as 0,005 sec and the total load time assumed as $1 \mathrm{sec}$.

a)

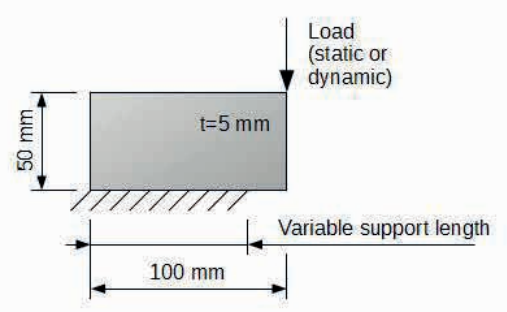

b)

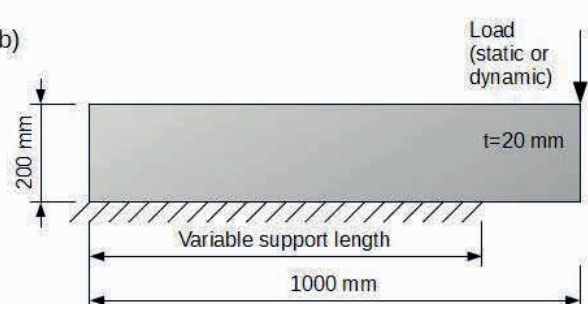

c)

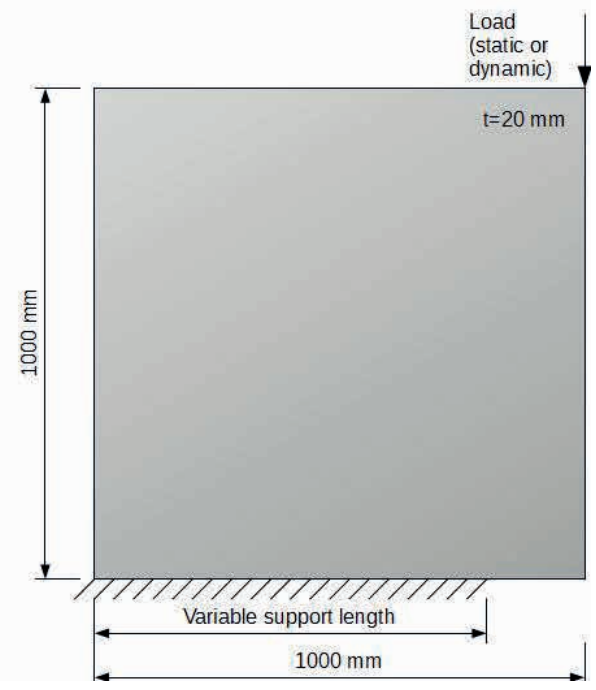

Fig. 6. Analyzed plate members: a) $A$ 100x50x5 mm, b) $B$ 1000x200x20 mm, c) $C$ 1000x1000x20 mm 


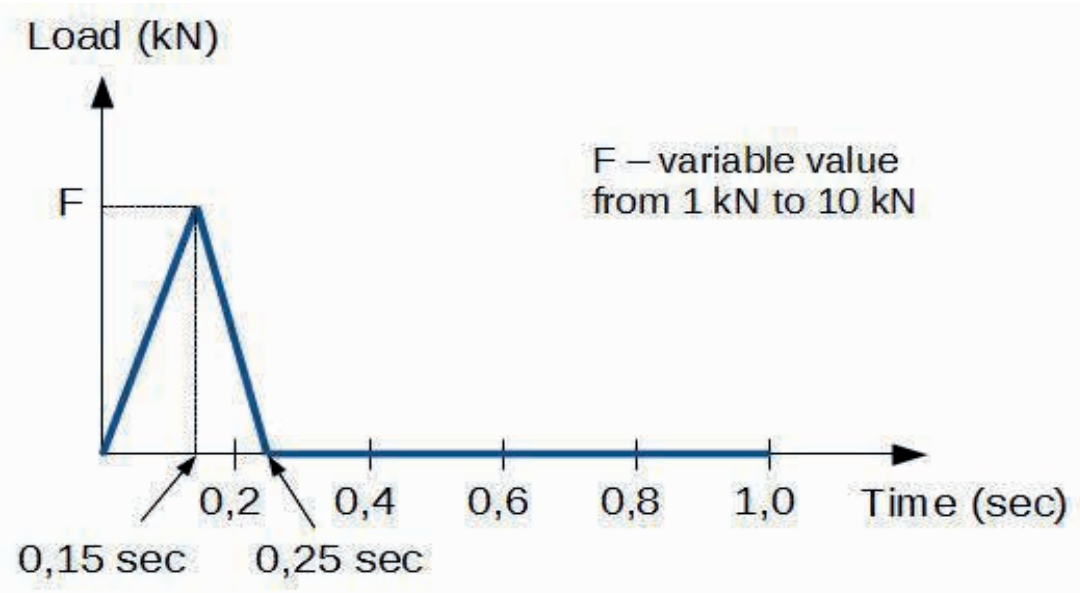

Fig. 7. Time history of the impact load [22]

\subsection{Numerical models}

For each of the three analysed structures, two Finite Element (FE) models were built. For each plate, one of the two models played the role of the pseudo-experimental model. It was the model with a larger number of finite elements, and it was named herein as a Dense Model (DM), the decision on the number of finite elements was preceded by an analysis of this number on the results obtained. The second model was named as a Sparse Model (SM), a significantly smaller number of finite elements introduced some inaccuracies into the results obtained from this model. The numerical models of the structures were created by using the MATLAB R2018a program. Four node plane stress elements (built as a combination of four general-purpose linear triangular plane stress elements) called planqe in Calfem was used [22]. Material parameters used in the numerical models are as follows: Young's Modulus $E=205 \mathrm{GPa}$, Poisson's Ratio $n=0,30$, density $r=7860 \mathrm{~kg} / \mathrm{m}^{3}$.

For the first analyzed member $A$, two numerical models were built - the Sparse Model A1 and the Dense Model A2. Model A1 consisted of 1250 finite elements i.e. 50 finite elements in the horizontal direction and 25 elements in the vertical direction. The model $A 2$ corresponded to the experimental research. The model $A 2$ consisted of 5000 finite elements i.e. 100 finite elements in the horizontal and 50 elements in the vertical direction. For the second analyzed plate $B$, the model $B 1$ consisted of 1000 finite elements i.e. 100 elements $\times 10$ elements. Model B2, corresponding to the experimental research, consisted of 4000 finite elements i.e. 200 elements x 20 elements. For the third analyzed plate member C, the Sparse Model $C 1$ consisted of 100 finite elements i.e. 10 elements x 10 elements. Model C2, corresponding to the experimental research, consisted of 400 finite elements i.e. 20 elements x 20 elements.

In Sparse Models i.e. A1, B1, C1 fixed support along the bottom edge on the selected fragment of the edge was modeled. The length of the fixed support was treated as unknown and denoted by $x$. This length $x$ was updated. For pseudo-experimental i.e. Dense Models $A 2, B 2, C 2$ support length was accurately determined and denoted by $S L$. The value of $x$ was updated to $S L$ and different $S L$ values were considered (from 1/20 of the plate length to the whole plate length). The selection of the parameters treated as unknowns was related 
to the previous experience of the authors, which shows that in real cases, the numerical modeling of the supports often has a decisive impact on the compatibility of experimental and numerical models.

\subsection{Updating of numerical models}

The pseudo-experimental models had four times as much finite elements than the updated models, which resulted in a structure error between the results obtained from both models. The displacements values obtained from models corresponding to the experimental research were rounded to the accuracy that can be obtained from DIC measurements.

The updated parameter of the sparse model was chosen so to minimize the differences between the values of selected magnitude obtained from the calculations performed for the updated model and the ones obtained from the calculations performed for the pseudo-experimental model. In the case of the static load, differences between displacement values of selected nodes of the models were minimized. In the case of the dynamic load, differences between affine parameters for selected quadrangular fragments of the models were minimized. It was being checked if using such parameters for updating models will give better results than using displacement values caused by the static load.

The numerical procedure used to update the numerical models solves nonlinear leastsquares curve fitting (nonlinear data-fitting) problems of the formula [22]:

$$
\begin{aligned}
& \min _{x}\|f(x)\|_{2}^{2}=\min _{x}\left(f_{1}(x)^{2}+f_{2}(x)^{2}+\ldots+f_{n}(x)^{2}\right) \\
& \min _{x}\|f(x)\|_{2}^{2}=\min _{x}\left(f_{1}(x)^{2}+f_{2}(x)^{2}+\ldots+f_{n}(x)^{2}\right)
\end{aligned}
$$

with lower and upper bounds $l b$ and $u b$ on the components of $x$.

A value of the support length of the Sparse Model $x$ was updated. The numerical procedure started at the point $x_{0}$ and found a minimum of the sum of squares of the difference of the displacements for static cases or difference of the affine parameters for the dynamic cases. The lower and upper bounds were defined so that the solution was always in the range $l b \leq x \leq u b$. For the $A 1$ model the lower bound was $0,005 \mathrm{~m}$ and the upper bound was $0,09 \mathrm{~m}$. For the $B 1$ and $C 1$ models the lower bound was $0,05 \mathrm{~m}$ and the upper bound was $0,90 \mathrm{~m}$. For all models the starting point $x_{0}$ was chosen randomly from the range between the lower bound and the upper bound.

\section{Results of updating of numerical models}

For the first updated Sparse Model A1, two cases of updating were considered. In the first case, the updated support length of the Model A was chosen to minimize the differences between the displacements caused by the static load (case 1). For the updated model the displacements of all nodes were taken into account. For the Dense Model A2, the displacements of the nodes in which locations were the same as the location of the nodes of the updated model were only taken into account. In the second case, the differences between the affine parameters' values for the quadrangular fragment of the models were minimized (case 2). It was decided to analyze the quadrangle of the highest possible length. Thus, four points of the most distant from each 
other were chosen. The selected fragment was determined by four points with the coordinates $(x, y)[\mathrm{m}]:(0,002 ; 0,048),(0,098 ; 0,048),(0,002 ; 0,002),(0,098 ; 0,002)$ (see Fig. 8).

It was assumed that in the case of experimental tests the whole plate will be observed by the DIC system using one camera. To take into account the accuracy of the DIC system, the displacements obtained for Dense Model A2 were rounded to 0,00001 m.

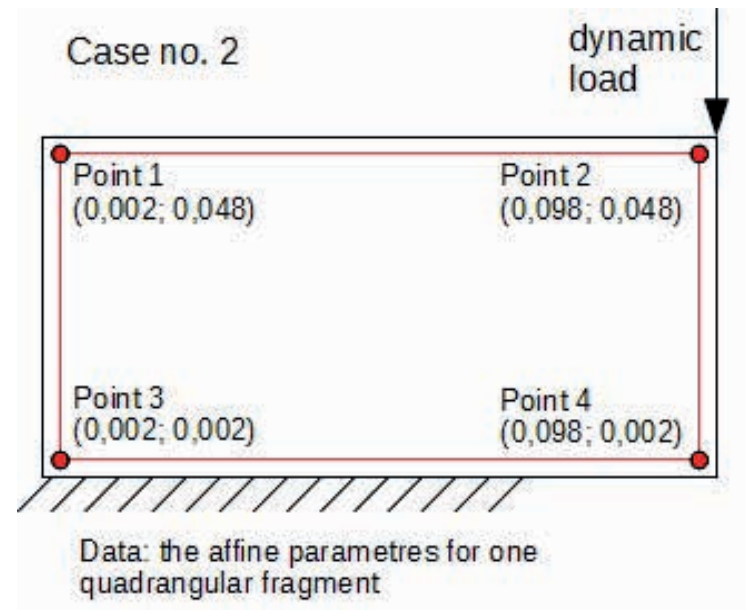

Fig. 8. Data for updating of numerical model $A$, case no. 2

The updating of the model $A 1$ was repeated 50 times for each considered case and for each value of the load from $1 \mathrm{kN}$ to $10 \mathrm{kN}$ to estimate a statistical description of the result of the model updating by calculation the following values: standard deviations, absolute errors, relative errors and the average value of each type error. The exemplary values of relative errors and their average value obtained from 50 calculations preformed for dynamic load $10 \mathrm{kN}$ is shown in Fig. 9.

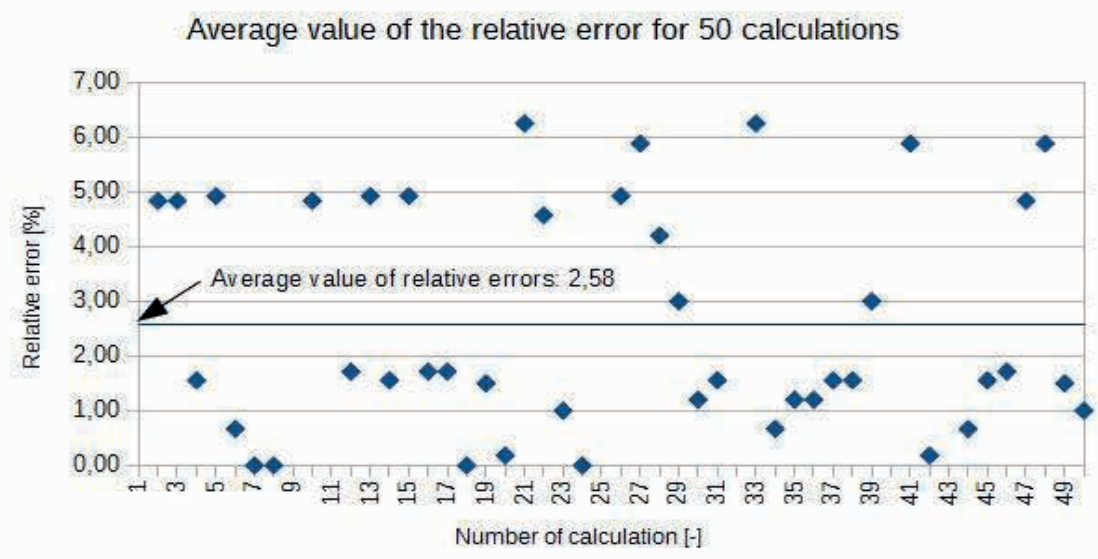

Fig. 9. The average value of relative error for the dynamic load $10 \mathrm{kN}$ 
The final results of updating of the numerical model $A 1$ for the static load and the dynamic load (from $1 \mathrm{kN}$ to $10 \mathrm{kN}$ ) are shown in Fig. 10.

The relationship between relative errors and loads

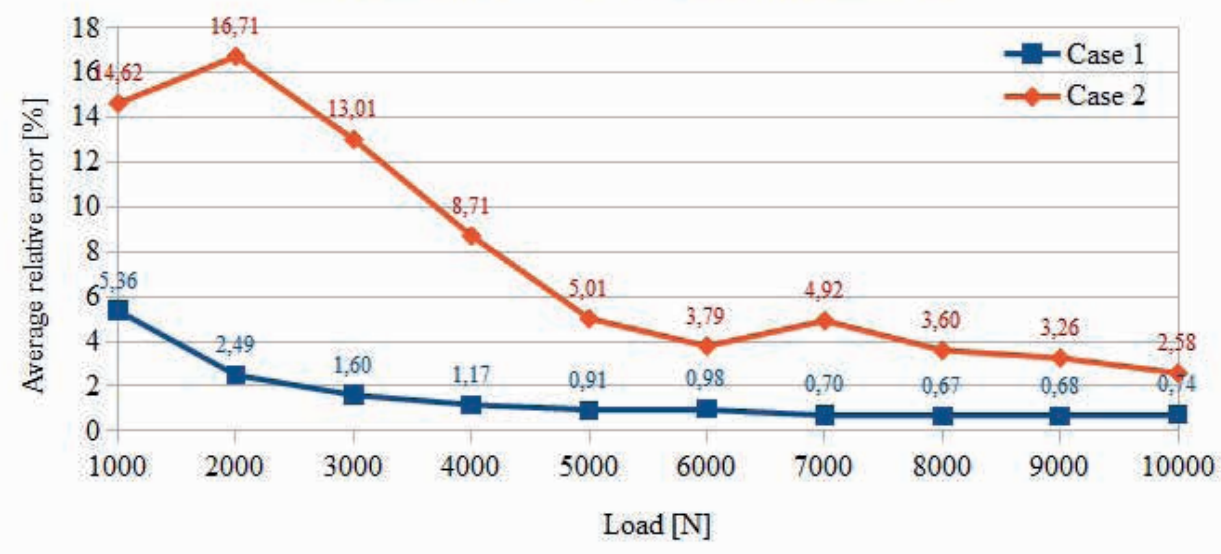

Fig. 10. Average values of the relative errors of updating the model $A 1$

For the second updated Sparse Model B1, five cases of updating of the numerical model were considered. The considered cases from 1 to 5 are as follows:

1) the differences between the displacements caused by the static load for all nodes of the model B1 and corresponding nodes of the Dense Model B2 were taken into account,

2 ) the differences between the displacements caused by the static load for selected nodes of the model B1 and corresponding nodes of the Dense Model B2 were taken into account, the selected nodes were located on the selected fragment $(100 \mathrm{~mm} \mathrm{x}$ $100 \mathrm{~mm}$ ) of the model as shown in Fig. 11,

3) the differences between the affine parameters values for the quadrangular fragment of the models were minimized, the selected fragment was determined by four points with the coordinates $(x, y)[\mathrm{m}]:(0,91 ; 0,14),(0,99 ; 0,14),(0,91 ; 0,06),(0,99 ; 0,06)$ as shown in Fig. 12 a,

4) the differences between the affine parameters values for the quadrangular fragment of the models were minimized, the selected fragment was determined by four points with the coordinates $(x, y)[\mathrm{m}]:(0,50 ; 0,14),(0,99 ; 0,14),(0,50 ; 0,06),(0,99 ; 0,06)$ as shown in Fig. 12 b,

5) the differences between the affine parameters values for the quadrangular fragment of the models were minimized, the selected fragment was determined by four points with the coordinates $(x, y)[\mathrm{m}]:(0,01 ; 0,14),(0,99 ; 0,14),(0,01 ; 0,06),(0,99 ; 0,06)$ as shown in Fig. $12 \mathrm{c}$.

In case no. 1, it was assumed that the experimental tests will be performed on the whole surface of the plate by the DIC Q-450 system using one camera. In order to take into account the accuracy of the DIC system, the displacements obtained for the Dense Model B2 were rounded to $0,0001 \mathrm{~m}$. In the cases no. 2 and 3 it was assumed that the experimental tests will be 
performed only on the selected fragment of the plate element i.e. $100 \mathrm{~mm}$ x $100 \mathrm{~mm}$ by using one camera. In order to take into account the accuracy of the DIC system, the displacements obtained for experimental model $B 2$ were rounded to $0,00001 \mathrm{~m}$. In the cases no. 4 and 5 it was assumed that the experimental tests will be carried out with the use of two cameras, one camera will record images of the two left points of the selected quadrangular fragment and the second camera will record images of the two right points of the selected quadrangular fragment. In order to take into account the accuracy of the DIC system, the displacements obtained for Dense Model B2 were rounded to 0,00001 m.

The updating of the model $B 1$ was performed 50 times for each case and for each value of the load. For each value of the updated parameter, a relative error and an absolute error were calculated and average values of every type of the errors. The final results of updating of the numerical model $B 1$ are shown in Fig. 13.

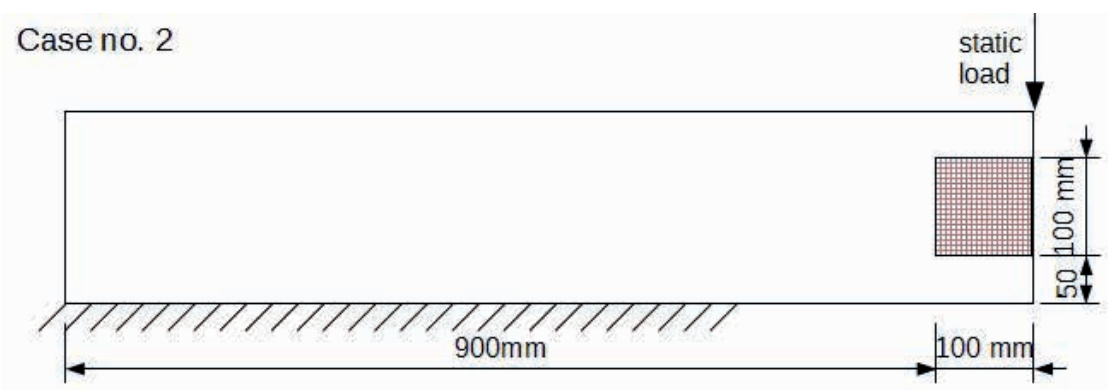

Data: the vertical and horizontal displacements of the nodes only from selected fragment

Fig. 11. Data for updating of numerical model B1, static load, case no. 2

a)

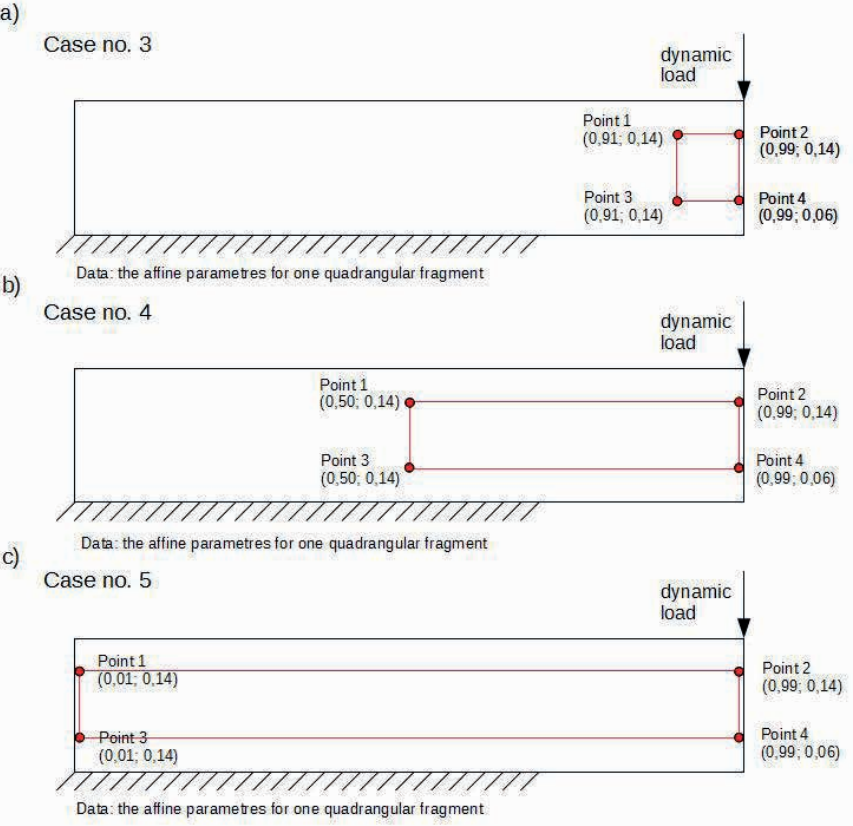

Fig. 12. Data for updating of numerical model B1, dynamic load: a) case no. 3 , b) case no. 4 , c) case no. 5 


\section{The relationship between relative errors and loads}

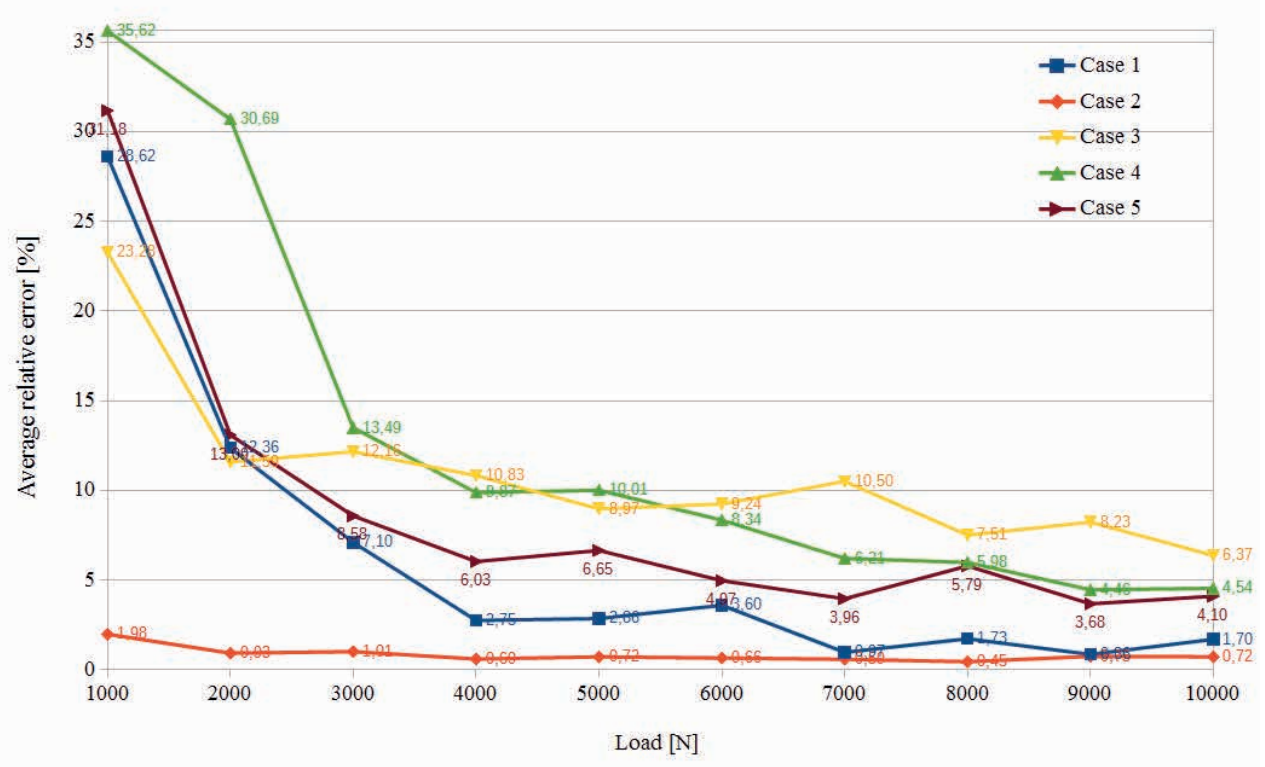

Fig. 13. Average values of the relative errors of updating the model B1, case no. 1-5

For the third updated Sparse Model C1 of the plate, at first, the updated support length of the model $C l$ was chosen to minimize the differences between the displacements caused by the static load for all nodes of the model C1 and for corresponding nodes of the Dense Model C2 (case 1). It was assumed that in the case of experimental tests the whole plate will be measured by the DIC Q-450 system using one camera. In order to take into account the accuracy of the DIC system, the displacements obtained for the Dense Model C2 were rounded to 0,0001 m. Then the differences between the displacements caused by the static load for selected nodes of the model Cl (located on the $100 \mathrm{~mm}$ x $100 \mathrm{~mm}$ fragment in the lower right corner of the plate) and corresponding nodes of the Dense Model C2 were taken into account (case 2). In this case, the displacements obtained for dense model $C 2$ were rounded to $0,00001 \mathrm{~m}$ and it was assumed that one camera will be used.

Next the updated support length of the model $C 1$ was chosen so as to minimize the differences between the affine parameters calculated on the basis of displacements caused by the dynamic load for three cases. The considered cases marked as 3, 4, 5 are as follows:

- case 3 - the differences between the affine parameters for the quadrangular fragment determined by four points with the coordinates $(x, y)[\mathrm{m}]:(0,10 ; 0,90),(0,90 ; 0,90)$, $(0,10 ; 0,10),(0,90 ; 0,10)$ were minimized, see Fig. 14 a,

- case 4 - the differences between the affine parameters for the quadrangular fragment determined by four points with the coordinates $(x, y)[\mathrm{m}]:(0,10 ; 0,40),(0,90 ; 0,40)$, $(0,10 ; 0,10),(0,90 ; 0,10)$ were minimized, see Fig. 14 b,

- case 5 - the differences between the affine parameters for the quadrangular fragment determined by four points with the coordinates $(x, y)[\mathrm{m}]:(0,60 ; 0,40),(0,90 ; 0,40)$, $(0,60 ; 0,10),(0,90 ; 0,10)$ were minimized, see Fig. 14 c. 


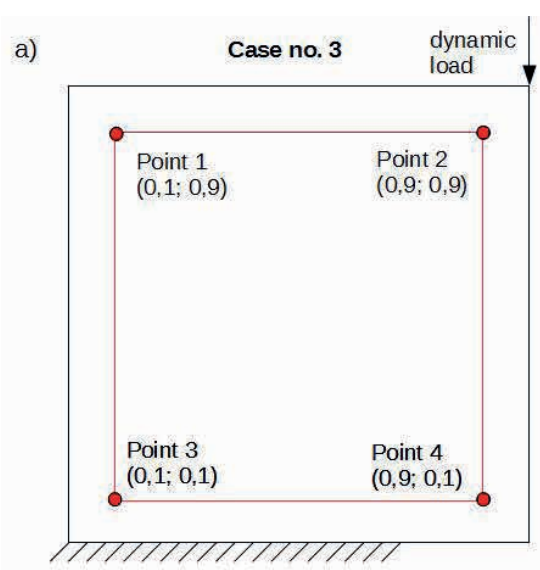

Data: the affine parametres for one quadrangular fragment

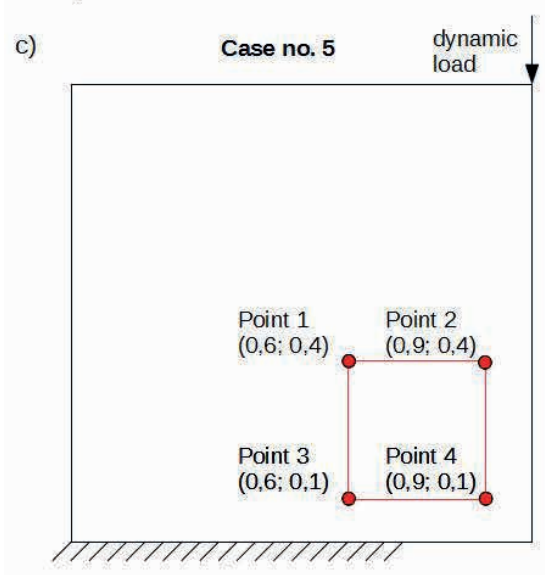

Data: the affine parametres for one quadrangular fragment

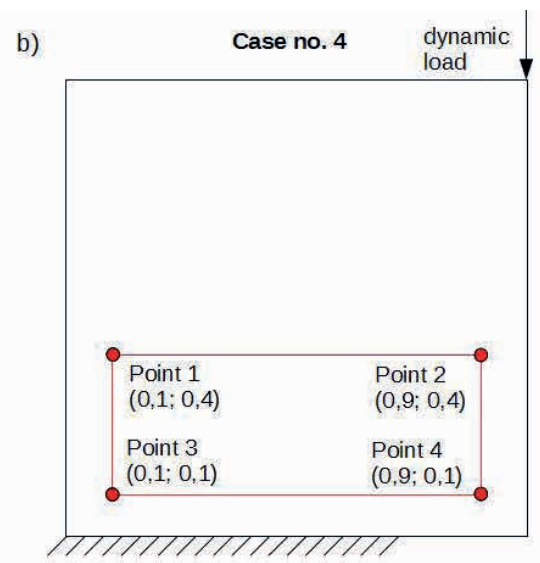

Data: the affine parametres for one quadrangular fragment

Fig. 14. Data for updating of numerical model $C 1$ : a) case no. 3, b) case no. 4, c) case no. 5

In cases 3-5 it was assumed that the experimental tests will be carried out in four parts of the plate with the use of two cameras or four cameras. In research with 2 cameras (it is the basic number of cameras in the DIC Q-450 system), the measurements will be made as follows: first the cameras will be set to the left of the plate and the measurements will be made on the left part of the plate in such a way that every camera will record images of one left point of the selected quadrangular fragment, next the cameras be moved to the right side and every camera will record images of one right point of the selected quadrangular fragment. In research with 4 cameras, the measurements will be made as follows: every camera will record images of one point of the selected quadrangular fragment. In order to take into account the accuracy of the DIC system, the displacements [m] obtained for the Dense Model C2 were rounded to $0,00001 \mathrm{~m}$.

The updating of the model $C 1$ was performed 50 times for each case and for each value of the load. For each value of the updated parameter errors are calculated. The final results of updating the numerical model $C 1$ are shown in Fig. 15. 


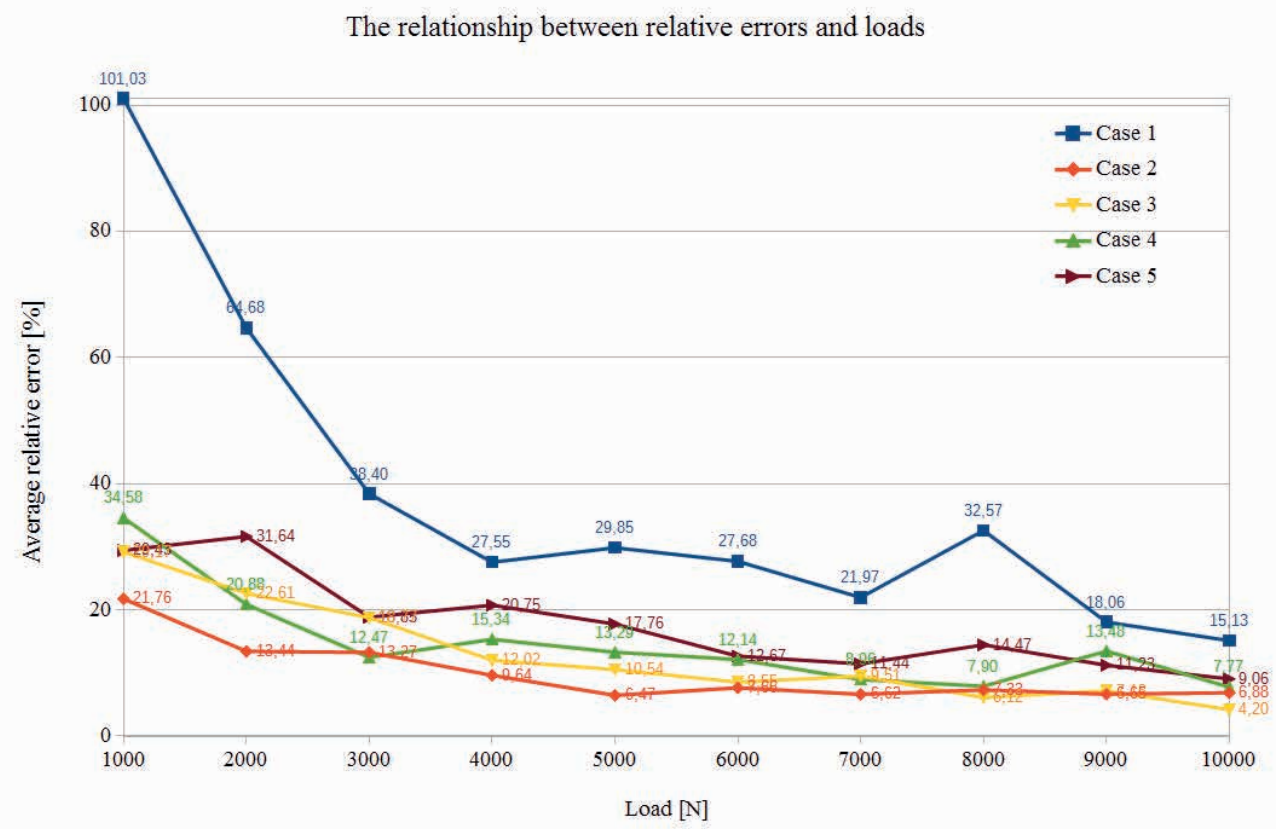

Fig. 15. Average values of the relative errors of updating the model C1, case no. 1-5

For more detailed analysis the results obtained for the load of $10 \mathrm{kN}$ were selected. For all analysed plates, i.e. $A, B, C$, average values of relative error were compared. In Table 2 there are presented individual updating cases, types of loads, types of data used for updating, and accuracy of DIC system included in the calculations and an expected number of cameras that were simulated in the experimental research.

As shown in Table 2, for member A the better result was obtained in case 1. For the plate $B$, the better results of updating models were obtained for the cases with a static load. The best result was obtained in case 2. Comparing the first two cases, it can be noticed that the DIC system's accuracy has a significant impact on the updating results. Comparing all cases with a dynamic load, it can be noticed that the best procedure taking into account the affine parameters was one used in case 5. The selected fragment for which the affine parameters were calculated, determined by four points in the corners of the plate (four points create the quadrangle with the possible longest sides) was the most advantageous. As shown in Table 2, the best result of model updating for the plate member $\mathrm{C}$ were obtained in case 3 . In this case the updating procedure considered affine parameters obtained for the square fragment of the plate member. The selected fragment of the area was determined by four nodes located close to the corners of the plate members. As would be expected, analyzing the cases with a static load it can be noticed that the DIC accuracy is very important in research - the greater accuracy, the better result of updating. The results obtained for updating procedures considering the dynamic load i.e. cases from 3 to 5 are similar to the result obtained in case 2 . 
Table 2. Summary of results for plates $A, B, C$

\begin{tabular}{|c|c|c|c|c|c|c|}
\hline Plate & $\begin{array}{l}\text { Updating } \\
\text { Case }\end{array}$ & Load type & $\begin{array}{l}\text { Data type using } \\
\text { for updating }\end{array}$ & $\begin{array}{l}\text { Accuracy of DIC } \\
\text { system included } \\
\text { in the calculations }\end{array}$ & $\begin{array}{l}\text { Expected } \\
\text { number } \\
\text { of cameras } \\
\text { in the } \\
\text { research }\end{array}$ & $\begin{array}{l}\text { Updating result } \\
\text { for load } 10 \mathrm{kN} \\
\text { (average value } \\
\text { of the relative error) }\end{array}$ \\
\hline \multirow[t]{2}{*}{$A$} & 1. & static & displacements & $0,00001 \mathrm{~m}$ & 1 & $0,74 \%$ \\
\hline & 2. & dynamic & affine parameters & $0,00001 \mathrm{~m}$ & 1 & $2,58 \%$ \\
\hline \multirow[t]{5}{*}{$B$} & 1. & static & displacements & $0,0001 \mathrm{~m}$ & 1 & $1,70 \%$ \\
\hline & 2. & static & displacements & $0,00001 \mathrm{~m}$ & 1 & $0,72 \%$ \\
\hline & 3. & dynamic & affine parameters & $0,00001 \mathrm{~m}$ & 1 & $6,37 \%$ \\
\hline & 4. & dynamic & affine parameters & $0,00001 \mathrm{~m}$ & 2 & $4,54 \%$ \\
\hline & 5. & dynamic & affine parameters & $0,00001 \mathrm{~m}$ & 2 & $4,10 \%$ \\
\hline \multirow[t]{5}{*}{$C$} & 1. & static & displacements & $0,0001 \mathrm{~m}$ & 1 & $15,13 \%$ \\
\hline & 2. & static & displacements & $0,00001 \mathrm{~m}$ & 1 & $6,88 \%$ \\
\hline & 3. & dynamic & affine parameters & $0,00001 \mathrm{~m}$ & 2 or 4 & $4,20 \%$ \\
\hline & 4. & dynamic & affine parameters & $0,00001 \mathrm{~m}$ & 2 or 4 & $7,77 \%$ \\
\hline & 5. & dynamic & affine parameters & $0,00001 \mathrm{~m}$ & 2 or 4 & $9,06 \%$ \\
\hline
\end{tabular}

As shown, for larger plates the use of the procedure with affine parameters can give better results than the procedure using the displacements caused by the static load. However, attention should be paid to the number of cameras that are expected to be used. More cameras mean more time-consuming and more complicated research, for example, due to the camera calibration or data analysis. For larger plates, the use of the procedure with affine parameters may be a better option, but there should be considered the difficulty of measurements by means of DIC system with several cameras. Moreover, in this paper for dynamic load, there were considered the cases with only one quadrangular fragment for which the affine parameters' values were calculated. However, the procedure can use a much larger number of affine parameters. The parameters can be obtained for at least as many quadrangles as they can be built on the nodes of the sparse model.

\section{Conclusion}

On the basis of the numerical analyses, the following some conclusion can be formulated:

- the DIC system can be helpful in updating of numerical models of structural elements,

- the DIC accuracy has a significant influence on the updating results,

- for larger members, the updating procedure taking into account the affine parameters in dynamics can give better results than the procedure based on displacements values caused by the static load.

The results of numerical simulations and statistical analyzes show that the DIC can be used for updating numerical models of steel plates in plane state of stress. For different size members, it is possible to create the test procedure that allows updating the numerical models in a quick and non-contact way. The presented procedures of numerical models updating were verified only in a numerical way. The next step of the work will be to check the proposed procedures with different unknown parameters and in an experimental way by carrying out research on the real elements by using the DIC Q-450 system and by using measurement data to update the numerical models. 


\section{References}

[1] Miller B., "Nieniszczące badania konstrukcji: dostrajanie modelu oraz identyfikacja obciążenia powodującego częściowe uplastycznienie", Zeszyty Naukowe Politechniki Rzeszowskiej, Budownictwo i Inżynieria Środowiska, no. 243, 45 (2007), pp. 125-134.

[2] Wang Y. H. et al., "Whole field sheet-metal tensile test using digital image correlation", Experimental Techniques, vol. 34, no. 2 (2010), pp. 54-59. https://doi.org/10.1111/j.1747-1567.2009.00483.x

[3] Digital Image Correlation (DIC). Available: http://www.dantecdynamics.com/digital-image-correlation [Accessed: 20 Dec 2019]

[4] Sutton M.A., Orteu J.J., Schreier H.W., Image Correlation for Shape, Motion and Deformation Measurements: Basic Concepts, Theory and Applications. New York: SPRINGER (2009), ISBN: 978-0-387-78746-6, e-ISBN: 978-0-387-78747-3. https://doi.org/10.1007/978-0-387-78747-3

[5] Szymczak T., Kowalewski Z. L., Brodecki A., "Metoda cyfrowej korelacji obrazu w badaniach materiałów i elementów", Dozór Techniczny, vol. 4 (2016), pp. 22-31.

[6] Q-450 SYSTEM Operation Manual, Dantec Dynamics (2013)

[7] Chu T. C., Ranson W. F., Sutton M. A., "Application of digital-image correlation techniques to experimental mechanics", Experimental Mechanics, no. 25 (1985), pp. 232-244. https://doi. org/10.1007/BF02325092

[8] Peters W. H. et al., "Applications of digital image correlation methods to rigid body mechanics", Optical Engineering, no. 22 (1983), pp. 738-742.

[9] Peters W. H., Ranson W. F., "Digital imaging technique in experimental stress analysis", Optical Engineering, no. 21 (1982), pp. 427-431. https://doi.org/10.1117/12.7972925

[10] Guoqing Gu et al., "Non-uniform illumination correction based on the retinex theory in digital image correlation measurement method", Optica Applicata, vol. XLVII, no. 2 (2017), pp. 199-208. https://doi.org/10.5277/oa170203

[11] Hack E., Lin X., Patterson E. A., Sebastian C. M., "A reference material for establishing uncertainties in full-field displacement measurements". Measurement Science and Technology, vol. 26, no. 7 (2015). https://doi.org/10.1088/0957-0233/26/7/075004

[12] Lutowski Z., Marciniak B., Marciniak T., Bujnowski S., "Precision of Sub-Pixel Image Displacement Measurements". Journal of Machine Construction and Maintenance, vol. 4 (2017), pp. 21-26.

[13] Zappa E., Matinmanesh A., Mazzoleni P., "Evaluation and improvement of digital image correlation uncertainty in dynamic conditions", Optics and Lasers in Engineering, vol. 59 (2014), pp. 82-92. https://doi.org/10.1016/j.optlaseng.2014.03.007

[14] Krawczyk Ł., Gołdyn M., Urban T., "O niedokładnościach systemów cyfrowej korelacji obrazu”, Journal of Civil Engineering, Environment and Architecture, vol. XXXIV, no. 64 (2017), pp/ 259-270. https://doi.org/10.7862/rb.2017.120

[15] Kamera szybka Phantom v341. Available: http://www.ects.pl/produkty/c84_kamery-szybkie/ p264_kamera-szybka-phantom-v341 [Accessed: 20.12.2019]

[16] Lord J. D., Digital Image Correlation (DIC). Modern Stress and Strain Analysis. A state of the art guide to measurement techniques. BSSM Technical Editors: J. Eaton Evans, J. M. Dulieu-Barton, R. L. Burguete (2009), pp. 14-15.

[17] Turoń B., Ziaja D., Miller B., "Wykrywanie uszkodzeń węzłów ramy stalowej z wykorzystaniem metody cyfrowej korelacji obrazu", Journal of Civil Engineering, Environment and Architecture, vol. XXXIV, no. 64 (2017), pp. 185-198. https://doi.org/10.7862/rb.2017.91

[18] Affine and Projective Transformations. Available: https://www.graphicsmill.com/docs/gm/ affine-and-projective-transformations.htm [Accessed: 20.12.2019] 
[19] Heckbert P. S. Fundamentals of Texture Mapping and Image Warping. Master's thesis, University of California at Berkeley, Department of Electrical Engineering and Computer Science, Berkeley 1989.

[20] Wang Y. Video Processing \& Communications. Two Dimensional Motion Estimation (Part I: Fundamentals \& Basic Techniques. Available: http://eeweb.poly.edu/ yao/EL6123old/motion2d part1_new.pdf [Accessed: 20 Dec 2019]

[21] Trebuňa F., Huňady R., Bobovský Z., Hagara M., "Results and Experiences from the Application of Digital Image Correlation in Operational Modal Analysis", Acta Polytechnica Hungarica, vol. 10, no. 5 (2013), pp. 159-174.

[22] CALFEM. A finite element toolbox. Version 3.4 (2004), ISBN: 91-8855823-1 
